\title{
Sensorless Vibration Diagnostics of Permanent Magnets Traction Electrical Motors-The Shaft Unbalance Example
}

\author{
M. Baranski, B. Bedkowski \\ 188 Rozdzienskiego Ave., 40-203 Katowice, Poland
}

\begin{abstract}
This work presents a new vibration diagnostic method of permanent magnets (PM) traction motors. Those machines are frequently used in electrical vehicles. The described method is very unique and innovative. Characteristic properties of PM machines are used in this method - EMF generated due to vibrations. There was analysed number of publications which describe vibration diagnostic methods and tests of electrical machines with permanent magnets and there was no method found to determine the technical condition of such machine basing on their own signals. The method of determination the technical condition of PM electrical machine basing on its own signals is the subject of patent application [1].
\end{abstract}

Keywords-vibrations; diagnostics; monitoring; electrical machine; permanent magnets

\section{INTRODUCTION}

Last year evolution in the magnetic materials production technology and dissemination field caused that traction electrical motors significant part are machines with permanent magnets. Their main of advantages are the reasons of their popularity: high efficiency, high power density, high torque overload and relatively simple construction (Table 1) [2-4].

This method advantage of detecting vibrations in PM electrical machines is that the measurement system does not require to use a sensors. Excitation circuit and armature winding perform a function of the sensor of vibration at the same time. Vibration measuring sensors are used ones, for scaling the measurement. Vibration measurement with this method can be performed on-line during normal operation of the machine [3-5].

TABLE I. THE LIST OF ELECTRICAL MACHINES PARAMETERS.

\begin{tabular}{|l|c|c|r|l|l|}
\hline Type of motor & \multirow{2}{*}{$h$} & $P$ & $n$ & & \multicolumn{1}{|c|}{$m$} \\
\cline { 3 - 6 } & & {$[\mathrm{kW}]$} & {$[1 / \mathrm{min}]$} & {$[\%]$} & {$[\mathrm{kg}]$} \\
\hline Asynchronous & 200 & 30.0 & 1472 & 92.5 & 265 \\
\hline DC & 160 & 34.7 & 1560 & 88.5 & 247 \\
\hline PM & 160 & 31.2 & 1500 & 91.8 & 110 \\
\hline
\end{tabular}

This diagnostic method of vibration caused by shaft unbalance of PM electric machines, which has a number of poles pairs $\mathrm{p}$ and works with the rotational speed $\mathrm{n}$, includes registration a waveform of voltage or current of diagnosed machine, perform frequency analysis and separation the frequencies $\mathrm{fl}$ and $\mathrm{f} 2$ defined by equations (1), (2). The unbalance of shaft in wind or hydroelectric power plants is often caused by damage of turbine. That is an excellent method of vibration diagnostics in those devices [5-7].

$$
\begin{aligned}
& f_{1}=\frac{(p-1) f}{p} . \\
& f_{2}=\frac{(p+1) f}{p} .
\end{aligned}
$$

where:

$\mathrm{f1}, \mathrm{f} 2$ - searched frequencies,

$\mathrm{p}$ - number of pole pairs,

$\mathrm{f}$ - first harmonic frequency of tested machine,

\section{THE GENESIS OF METHOD}

The idea of using a PM machine as a vibration sensor appeared during the winding resistance measurements of such machines. When something is vibrating in vicinity of PM machine the measure of winding resistance become impossible because of disruptions. There is no such phenomena during the measure of winding resistance of induction machine, in similar environment. The electromotive force is inducted when the machine with permanent magnets is vibrating. That EMF introduce distortions and the measure of winding resistance is impossible. This is a serious problem for example during registration of winding resistance for determination of the winding temperature rise after the heating test (Figure1.) [2-7].

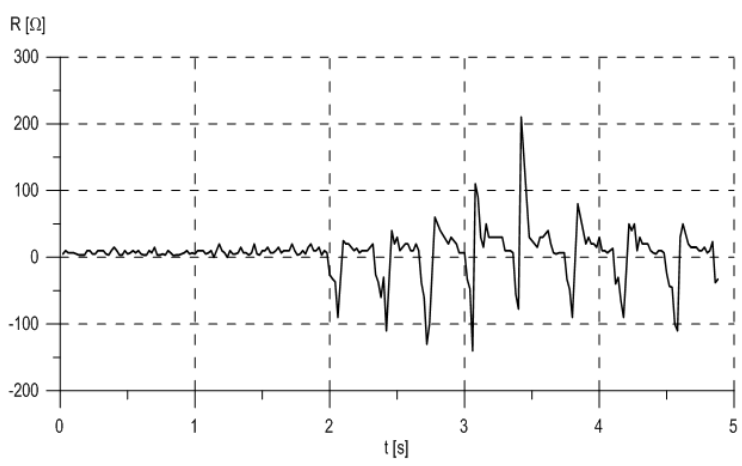

FIGURE I. DISRUPTIONS DURING THE RESISTANCE MEASUREMENTS

\section{PM MACHINE AS A VIBRATION SENSOR}

When the problem was analysed a similarity between PM machine and an electrodynamic sensor which is used to 
measure vibrations has been observed (Figure2a.). An electrodynamic sensor is characterized by [8-9]:

simple construction - a permanent magnet hanged on a spring inside a coil. The permanent magnet moves inside the coil and generates a voltage on terminals of the coil. The voltage signal is proportional to vibrations. There are also constructions where a coil moves and the permanent magnet is fixed rigidly to the chassis, sensitivity depends on the number of turns in the coil, the supply is no required for the sensor.

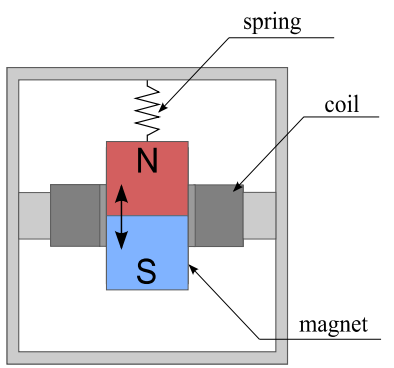

a)

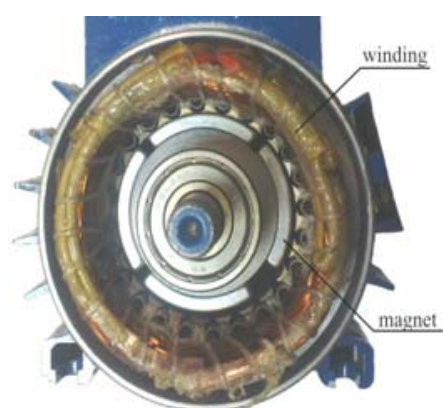

b)
FIGURE II. A) AN ELECTRODYNAMIC SENSOR, B) PM MACHINE.

There are some similarities can be noted when the comparison of PM machine with electrodynamic sensor was made (Figure2b.):

a similar structure - permanent magnets and coils (winding). While the sensor is exposed to the vibrations an EMF is generated. That EMF signal can be used for vibration analysis,

greater number of turns and pole pairs makes the signal greater. That means the sensitivity is dependent on the number of turns in the coil - in analogy to the electrodynamic sensor.

\section{THE LABORATORY TEST RESULTS}

The permanent magnets traction motors and generators used in renewable energy, usually work with all kind of inverters, controllers and electronic commutators. In these cases, we must remember that are dealing with non-sinusoidal waveforms. The frequency analysis those waveforms often is difficult. The waveform of current is close to sinusoid, but voltage has number of highest harmonics which must be filtered using passive or active different kinds of filters[10-12]. Below presents frequency analysis of Komel's motor current of type: SMwsPA132S4 (Figure3.) and parameters:

$$
I_{N}=160[\mathrm{~A}], P_{N}=15[\mathrm{~kW}], n_{N}=3400[1 / \mathrm{min}] .
$$

The machine was supplied with inverter SKAI (Figure4.). The analysis was made for traction motor with good technical conditions (Figure5a.) and for machine with additional mass (unbalanced) on shaft (Figure5b.). In the motor current spectrum with additional mass on shaft can be observed visibility of harmonics derived from rotational speed.

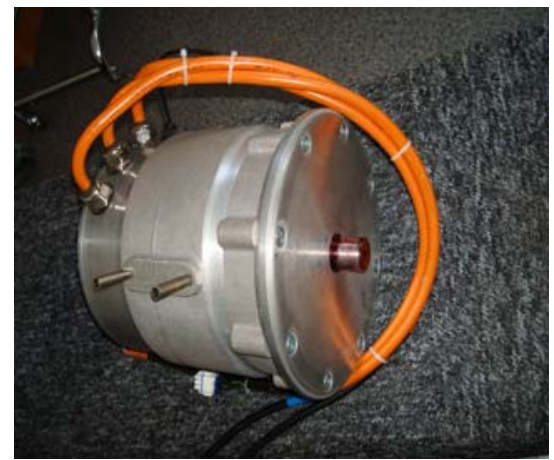

FIGURE III. THE TRACTION MOTOR OF TYPE: SMWSPA132S4 MADE BY KOMEL.

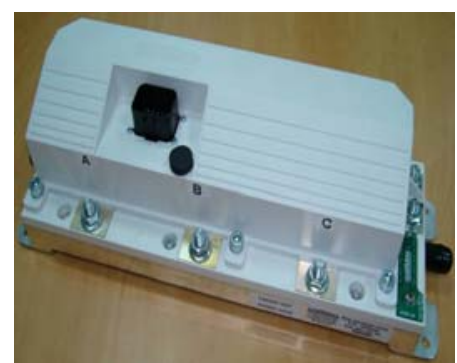

FIGURE IV. THE INVERTER SKAI.
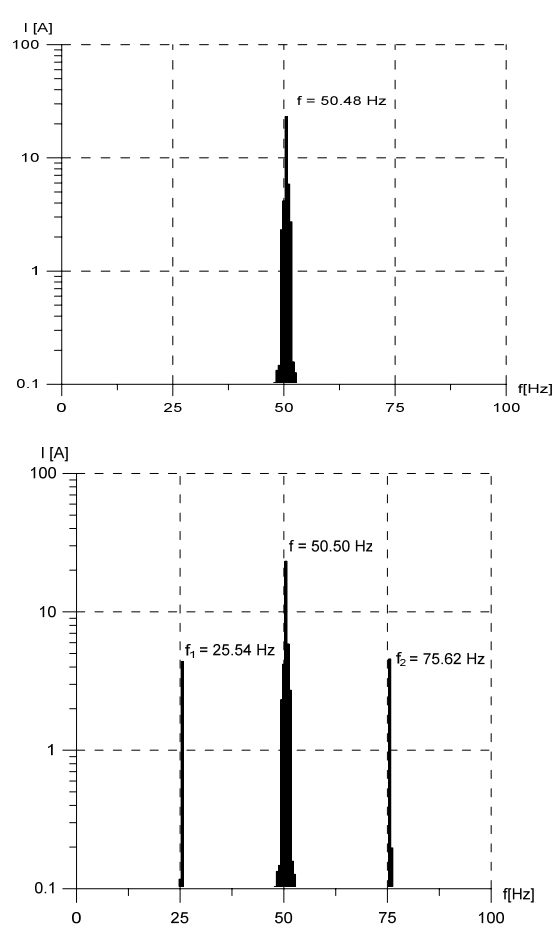

FIGURE V. TEST RESULTS OF SMWSPA132S4: A - MACHINE WITH GOOD TECHNICAL CONDITIONS, B - MACHINE WITH ADDITIONAL MASS (UNBALANCED) ON SHAFT. 
TABLE II. THE CALCULATION AND TEST RESULTS OF SMWSPA132S4.

\begin{tabular}{|l|c|c|c|}
\hline \multirow{2}{*}{ Frequency } & $f$ & $f_{1}$ & $f_{2}$ \\
\cline { 2 - 4 } & {$[\mathrm{Hz}]$} & {$[\mathrm{Hz}]$} & {$[\mathrm{Hz}]$} \\
\hline \multirow{2}{*}{ Calculation results (1) and (2) } & 50.00 & 25.00 & 75.00 \\
\cline { 2 - 4 } & 50.50 & 25.25 & 75.75 \\
\hline Test Results & 50.50 & 25.54 & 75.62 \\
\hline \\
V CONCLUSIONS
\end{tabular}

The calculations, simulations and tests confirm the effectiveness of new vibration diagnostic method for machines excited by permanent magnets, where vibrations were created as a result of unbalance (Figure5., Table 2). The analysis shows the possibility to use the machine with permanent magnets as a vibration sensor for itself. This approach is innovative and custom. The author never encountered such an application for PM machines, where the assessment of the intensity of the vibration specific properties of the machine are used [13-16]. Presented diagnostic method greatly simplifies measure of vibration in PM machines, according to the author who makes researches of machines in the laboratory, as well as diagnostics of electrical machines operating in the industry. The method does not require to use the expensive sensors and diagnostician does not care about their assembly, which in some cases is an important issue. Using additional equipment for FFT analysis of the voltage or current signal the method allows on-line diagnostics also [17-18].

\section{ACKNOWLEDGMENTS}

Scientific work financed by state funds for science in 2013-2015, as a project No. 413/L-4/2012 named "Vibroacoustic diagnostic method of traction permanent magnets motors and generators based on the own signals" realized in Institute of Electrical Drives and Machines "KOMEL".

\section{REFERENCES}

[1] M. Barański, T. Glinka, "Vibration diagnostic method of permanent magnets generators - detecting of vibrations caused by unbalance", PL Patent application P.405669.

[2] M.Barański, Vibration diagnostic method of permanent magnets generators - detecting of vibrations caused by unbalance, Przegląd Elektrotechniczny, 6/2014, pp. 236-239, Poland,

[3] M.Barański, New vibration diagnostic method of PM generators and traction motors - detecting of vibrations caused by unbalance, Energycon Conference materials, IEEEXplore, 2014, pp. 28-32,Croatia.

[4] M.Barański, Vibration diagnostic method of permanent magnets generators - detecting of vibrations caused by unbalance, EVER Conference materials, IEEEXplore, 2014, pp. 1-6, Monako.

[5] M.Barański, New vibration diagnostic method of PM generators and traction motors - detecting of vibrations caused by unbalance, Maszyny Elektryczne: Zeszyty Problemowe, 2014, Poland.

[6] M.Barański, PM Electrical Machines Diagnostic - Methods Selected, ICEMDS Conference materials, 2014, Spain.

[7] M.Barański, A. Decner, A. Polak, Selected Diagnostic Methods of Electrical Machines Operating in Industrial Conditions, IEEE Transactions on Dielectrics and Electrical Insulation, 5/2014, pp. 2047-2054.

[8] M.Barański, Tomasz Jarek, Analysis of PMSM Vibrations Based on Back-EMF Measurements, ICEM Conference materials, 2014,Germany.
[9] M.Barański and Bedkowski Bartlomiej, Electrical machine with permanent magnets as a vibration sensor - a test stand model, ICEM Conference materials, 2014, Germany.

[10] M. Maciążek, M. Pasko, D. Buła, Optimization of time in Active Power Filter control, $8^{\text {th }}$ International Workshop OPEE, 2007.

[11] M. Maciążek, M. Pasko, D. Grabowski, Active power filters-optimization of sizing and placement, Technical Sciences, 2013

[12] M. Maciążek, M. Pasko, Prediction in control systems of active power filters, Przegląd Elektrotechniczny, Poland, 210

[13] D. Torregrossa, "Multiphysics Finite-Element Modeling for Vibration and Acoustic Analysis of Permanent Magnet Synchronous Machine", IEEE Transactions On Energy Conversion, 2011, pp 490-500.

[14] R. Islam, "Analytical Model for Predicting Noise and Vibration in Permanent-Magnet Synchronous Motors", IEEE Transactions On Industry Applications, 2010, pp. 2346-2354.

[15] S. Lakshmikanth, K.R. Natraj and K.R. Rekha, "Noise and Vibration Reduction in Permanent Magnet Synchronous Motors -A Review", International Journal of Electrical and Computer Engineering, 2012, p.405.

[16] S. Nandi, H.A. Toliyat, "Condition monitoring and fault diagnosis of electrical machines-a review", Industry Applications Conference, 1999, pp.197-204

[17] A. Decner, Remote monitoring of electric machines, Maszyny Elektryczne: Zeszyty Problemowe, Katowice, Poland, 2011.

[18] M. Barański, A.Decner, Telemetry in diagnosis of electrical machines, Maszyny Elektryczne: Zeszyty Problemowe, Katowice, Poland, 2012, pp. 29-31. 